\title{
Children and marital dissolution in China
}

\author{
Kim Qinzi Xu ${ }^{1}$ \\ Accepted: 25 November 2021 / Published online: 7 March 2022 \\ (c) The Author(s) 2022
}

\begin{abstract}
Using data for women from the 2010, 2012 and 2014 Chinese Family Panel Studies, this study investigated several aspects of children's effects on the risk of marital dissolution, including the number of children, their age and sex composition, and the timing of conception relative to marriage. Because these explanatory variables are potentially endogenous, marital dissolution was jointly modelled with the processes of marriage formation, marital childbearing and nonmarital childbearing, and the sequencing of events and unobserved correlation across processes accounted for. The results demonstrated that childlessness significantly elevates the risk of divorce whereas the first child has the strongest marriage stabilising effect. Reflecting the strong son preference in rural China, having boys was shown to markedly reduce the risk of parental divorce among rural women. Whether a child is conceived within or out of wedlock has no significant causal effect on marital dissolution insofar as it belongs to both parents. However, positive residual correlation between the processes of divorce and nonmarital childbearing suggests the potential selection of women with non-traditional family behaviours into marital dissolution.
\end{abstract}

Keywords China $\cdot$ Marital dissolution $\cdot$ Children $\cdot$ Simultaneous equations

\section{Introduction}

Children, as one of the most important investments a couple makes in their relationship, have long been considered a deterrent to divorce. The presence of children could strengthen the marital bond by encouraging spousal interdependence, while parental feelings of obligation towards children are considered pivotal to martial stability. Although it is reasonable to expect an inhibiting effect of children on marital dissolution, existing literature has offered no consensus on the nature and direction of this effect. Childless families have generally been found to have an elevated risk of divorce compared to families with children, but children's

Kim Qinzi Xu

kim.xu@anu.edu.au

1 School of Demography, ANU, Canberra, Australia 
marriage-stabilising effects do not seem to increase with the number of children (Heaton, 1990; Thornton, 1977). Some studies have maintained that the number of children does not have significant effects on marriage stability; what mattered instead was the presence of infant and preschool children (Cherlin, 1977; Waite \& Lillard, 1991; Todesco, 2011). The timing of conceptions/births relative to marriage is another aspect of children's effects on marital disruption. Cherlin (1977), for example, found that children born before marriage destabilised rather than stabilised marriage. Meanwhile, Morgan et al. (1988) drew attention to the effect of children's sex composition on marital disruption, arguing that sons have more marriage stabilising effects than daughters. A cursory review of existing literature demonstrates the complex and multidimensional nature of children's effects on marital dissolution.

These effects are further complicated by the potential for reverse causation. Women in relationships more prone to disruption may deliberately postpone or avoid childbearing (Lillard \& Waite, 1993). Moreover, the direct effects of children on divorce could be confounded by the existence of joint determination (selectivity). Consider the positive link between nonmarital childbearing and marital dissolution found in Cherlin (1977). This association could indicate the existence of selection effects rather than a causal relationship. Perhaps an individual with less traditional family values is more prone to both nonmarital childbearing and divorce. Ignoring this issue of endogeneity could therefore bias estimates of the casual effect of children on marital dissolution.

This study aims to provide a comprehensive analysis of the multifaceted effects of children on marital dissolution, including the number of children, their age and sex composition, and whether a child was conceived/born within or outside of marriage. Special attention is paid to distinguishing the direct effects of children on divorce from other confounding factors as well as joint determination. The latter is achieved by modelling marital dissolution simultaneously with the family processes that result in key determinants, while controlling for the sequencing of life course events and unobserved correlation (this procedure will be explained later in detail). The focus is on China, where divorce rates have rapidly increased over recent decades, but traditional family norms have continued to hold sway (Wang \& Zhou, 2010). To this day, having children, especially sons, constitutes the primary function of marriage (Attané, 2009). Despite their importance to a marital union, however, the effects of children on marital stability remain underexplored. With few exceptions (Xu et al., 2015), existing studies on the determinants of divorce have usually included the number of children as a control variable (Ma et al., 2018; Zeng et al., 2002).

The present study extends the existing literature in three main ways. Firstly, it elucidates the conditions under which children stabilise marriage in China by taking into account the interplay between parity and children's age, and between children's sex composition and the number of children. Further, it expands previous work by paying close attention to the timing of conception/ birth of a child relative to marriage. Secondly, remarriages are included to examine the effect of stepchildren on marital stability. Thirdly, by controlling for joint determination, it distinguishes causal effects from potentially spurious associations (Baizán, Asssve \& Billari, 
2003; Upchurch et al., 2002). This analysis uses data for women from the 2010, 2012 and 2014 Chinese Family Panel Studies (CFPS).

\section{Theorectical perspectives and past research}

Several aspects of children's effects on marital stability have been emphasised in the existing literature: the presence and number of children, their ages, the sex composition of children and whether a child was conceived/born within or outside of marriage. From a dynamic life course perspective, some studies have further emphasised that marital dissolution and childbearing are interrelated family processes.

\section{The number of children, children's age and marital dissolution}

There are three sets of reasons why the presence of children, especially younger children, may inhibit marital dissolution. The first, proposed by Becker et al. (1977), posits that children are a form of marital-specific capital that loses much of its value outside of marriage. Young children, in particular, constitute more marital-specific capital compared to older children because parents tend to spend more time with younger children. The second perspective maintains that martial stability stems from a sexual division of labour, with the husband specialising in paid work and the wife in domestic labour (Parsons, 1949). In this view, childbearing and childrearing strengthen marital stability by increasing gender role specialisation and interdependence between husband and wife. Infant and young children have a greater protective effect on marriage, as they require a more complete sexual division of labour. Specifically, women with young children may be more dependent on a husband's income. The third perspective argues that the stability of marriage depends partly on the strength of barriers against marital disruption (Levinger, 1965). According to Levinger, parental feelings of obligation towards dependent children, together with other factors such as obligations to the marital bond and perhaps a religious affiliation, are sources of barrier strength. Young children more dependent on parental care could have more protective effects on marriage.

Empirical studies have generally demonstrated a positive association between the presence of children and marital stability. Various studies in the US and European countries have found that, after accounting for the duration of marriage and other confounding variables, childlessness significantly elevates the risk of marital disruption (Berrington \& Diamond, 1999; Morgan \& Rindfuss, 1985; Andersson, 1997; Diekmann \& Engelhardt, 1999, Todesco, 2011). There is, however, a non-linear relationship between the number of children and the risk of divorce. Becker et al. (1977) observed that the first two children discourage divorce more than additional children, whereas Murphy (1985) and Heaton (1990) demonstrated that both childless families and larger families have higher risks of divorce.

Other studies have found that the presence of young children, especially infant and preschool children, stabilised marriage, but older children had little or even negative effects on martial stability (Bracher et al., 1993; Cherlin, 1977). In a detailed 
analysis, Lillard \& Waite (1991) emphasised the interaction between parity and children's age. The authors found that a child stabilises marriage when it was aged five or younger, although this effect was only significant for the firstborn child but not for additional births. In contrast, a child older than 12 years significantly increases the risk of disruption regardless of parity. The authors argued that children may become a source of marital tension as they get older. And as they reach adulthood and leave home, their deterrence effect on divorce would decline as parents need to give up little contact with them after the dissolution of marriage.

Children's effect on divorce could vary by societal contexts. In Brazil, the presence of children, especially young children, was found to increase the risk of union dissolution (Leone \& Hinde, 2008). This was attributed to the stress associated with care for younger children. In contrast, a recent study in China observed a negative association between the number of children and divorce, even if these children were older than age 13 (Xu et al., 2015). It remains unknown whether the children's age has an independent effect on divorce risk in China, and whether this effect varies by parity.

\section{Sex composition of children and marital dissolution}

The sex composition of children is another important factor influencing marital stability. The 'father involvement hypothesis' proposed by Morgan et al. (1988) posits that families with sons are less at risk of marital disruption because fathers play a more active role in socialising sons compared to daughters. This creates interdependence between spouses and increases marital solidarity and stability. An alternative perspective emphasises a society's gender preference for children. In countries with strong son-preference, sons were considered to embody more marital-specific capital compared to daughters (Bose \& South, 2003). In patriarchal and patrilineal societies, having sons could further consolidate the women's position in the husband's family, making divorce harder to justify (Bose \& South, 2003). Sex composition of children may have little effect on the risk of divorce in more gender-egalitarian societies. Morgan and Pollard (2002) found that the effects of having sons on divorce had sharply declined in the US. A study in Australia found no significant effect of children's sex composition on divorce (Bracher et al., 1993), whereas one in Sweden showed that the risk of divorce was lower among parents who had achieved their desired sex composition of children, i.e., one girl and one boy (Andersson \& Woldemicael, 2001).

\section{Stepchildren, premarital conception and marital dissolution}

Children born out of marriage with a different biological parent could have little or a negative effect on marriage stability. They are generally not considered a marital-specific capital, nor would they inspire a strong feeling of obligation from the non-biological parent (Todesco, 2011). Remarriages involving the presence of stepchildren have been shown to be more prone to disruption than those without stepchildren (Waite \& Lillard, 1991). Some authors have further argued that children 
conceived/born outside of marriage have disruptive effects on parental marriage, even if they are biologically related to both parents. Becker et al. (1977) posited that premarital conception could prompt women to enter marriage quickly, thus increasing their chance of accepting a mismatch. Others maintain that couples engaging in premarital sexual behaviour may possess traits that make them more susceptible to marital disruption. These couples are often characterised as having more individualistic views and weaker adherence to traditional norms including the permanence of marriage (Thomson \& Collella, 1992), weaker relationship commitment (Axinn \& Thornton, 1992; Kahn \& London, 1991), or poorer problem-solving abilities (Cohan \& Kleinbaum, 2002).

Existing evidence in Western societies has generally confirmed a negative association between premarital births and marital disruption (Andersson, 1997; Bracher et al., 1993; Cherlin, 1977; Waite \& Lillard, 1991). However, by distinguishing between premarital births and premarital conceptions leading to marital births, Bracher et al. (1993) and Waite and Lillard (1991) found that although the risk of disruption was higher among women with premarital births, premarital conception, considered by itself, does not have an independent effect on the stability of parental marriage. In China, two recent studies have found a disruptive effect of premarital conception on marriage (Ma et al., 2018; Xu et al., 2015). It is unknown whether this association reflects the contribution of conceptions that translated into premarital births.

The negative association between premarital births and marital disruption has often been attributed to the potential of a selection effect (Bracher et al., 1993). However, most empirical studies have paid little attention to distinguishing causal effects from selection effects. The extent to which women with premarital sexual and childbearing experiences are selected into marital dissolution remain largely unexplored.

\section{Marital dissolution and childbearing as joint processes}

From a dynamic life course perspective, a strand of literature has emphasised the interrelated nature of family processes (Lillard, 1993; Lillard \& Waite, 1993; Lillard et al., 1995; Upchurch et al., 2002). These studies emphasise that an individual makes sequential and joint decisions about life course events within the constraints and opportunities available to them. The decisions are sequential in the sense that an initial decision of, for instance, entering marriage will influence the risk of subsequent events such as divorce and childbearing. At the same time, all life course events are simultaneously influenced by one's characteristics, including socioeconomic status, family background and personal traits and value orientations. Some of these characteristics may be unobserved, leading to potential residual correlation across processes. This issue of endogeneity needs to be accounted for to discern direct relationships between interrelated life course events such as divorce and childbearing.

Two important studies by Waite and Lillard were the first to pay attention to the interrelated processes of divorce and childbearing. Waite and Lillard (1991) showed 
that children affected the risk of divorce, whereas Lillard and Waite (1993) demonstrated that the reverse was also true; i.e., the risk of disruption faced by a married woman also decreased her likelihood of having a child within that marriage. A more recent study found a significant correlation of residuals between the processes of union dissolution and childbearing following conception within the union, suggesting the existence of unobserved individual characteristics that affect both processes in similar ways (Leone \& Hinde, 2008). Leone and Hinde emphasised that, without controlling for joint determination, estimates of the direct effects of children on union dissolution were biased.

As noted earlier, ignoring the potential for selectivity could be particularly problematic in analysis of the effect of premarital conceptions/births on marital dissolution. A large body of literature has focused on discerning the direct effects of premarital cohabitation on subsequent marital disruption from selection effects (Axinn \& Thornton, 1992; Lillard et al., 1995; Zhang, 2017). Although cohabitation and nonmarital childbearing are highly correlated processes (Brien et al., 1999), little if any attention has been paid to the effects of premarital conceptions/births on marital dissolution.

\section{The Chinese context and hypotheses}

China has a long tradition of universal marriage and a low level of divorce. In traditional China, marriage was parent-arranged, and its primary function was deemed to be continuation of the family line by the procreation of sons (Lee \& Wang, 1999). Under traditional legal systems, divorce was only allowed under a handful of conditions, the most important of which was a wife's failure to have sons (Wong, 1982). Although no-fault divorce has been permitted in China since 1950, divorce rates remained low through the 1970 s owing to persistent stigma associated with divorce and high administrative barriers to obtaining it (Platte, 1988). Occurrences of divorce began to steadily increase after the launch of economic reform and openingup policies in the late 1970s (Ma et al., 2018; Zeng et al., 2002). In the reform-era, increased exposure to Western ideas and cultures has promoted changing attitudes toward marriage and divorce. Love and companionship between spouses have been increasingly considered an important foundation of marriage, while growing emphasis has been placed on marital quality (Yan, 2003). In 1981, administrative barriers to divorce were relaxed when compulsory court-mandated mediation before divorce was abandoned (Huang, 2005). Unilateral divorce was further allowed from 2001 in circumstance of domestic violence and extramarital affairs (Sun \& Zhao, 2016).

Despite substantial changes in family behaviours, the importance of marriage and family continuation remains little diminished in contemporary China. This is reflected in the country's near universal marriage and childbearing (Zhao, Xu and Yuan 2017). Nowadays, young people are less willing to endure unhappy marriages, but many continue to believe that divorce should be avoided at all costs for the sake of children. In the 2014 wave of the CFPS, just below $85 \%$ of women born after 1970 agreed to the statement that "divorce is always harmful to the child", and about $61 \%$ of them agreed that "parents should never get divorced 
for the sake of the child even if they are unhappy about their marriage" (author's own calculation). Becker et al. (1977) argued that children deter divorce because they represent an important form of marital-specific investment. This is perhaps especially true in the Chinese context. It is therefore expected that the presence of children would significantly reduce the risk of divorce. In other words, having children is likely to lower the risk of divorce compared to families with no children (Hypothesis 1a).

Perhaps owing to the costs and stress associated with childcare in large families, previous studies have often observed a J-shaped relationship between divorce and the number of children (Berker et al., 1977; Heaton, 1990; Waite \& Lillard, 1991; $\mathrm{Xu}$ et al., 2015). However, the parity at which divorce risk was the lowest was found to vary over time and differ in various societies. This may in part be attributable to varying preferences for the desired family size over time and in different societies. In a society with strong two-child family norm, for instance, having a third or higher order births may constitute a source of strain more so than that in a society where higher fertility is the norm. In the Chinese context, rising divorce over the past few decades has occurred in tandem with drastic fertility decline since the implementation of the One Child Policy in 1979. Variations in provincial fertility policies notwithstanding, the vast majority of urban residents were subjected to the 'onechild-per-couple' policy (with some exceptions including the death or disability of the first child, and childbearing in remarriage following divorce or widowhood) (Gu et al., 2007). For urban families, having the first child is likely to significantly reduce divorce risk, but having a second and higher order birth is unlikely to have a significant effect on the risk of disruption due to their low occurrences (hypothesis 1b). Even in the context of the One Child policy, having two children was generally allowed among rural residents in most provinces since 1984 (Gu et al., 2007). A survey conducted in 1988 and updated in 1993 showed that when asked about their ideal family size, the majority of rural parents said that they wanted two children (Greenhalgh \& Li, 1995). For rural residents, the first two children can be expected to discourage divorce more so than additional births (Hypothesis 1c).

The presence of young children, especially infant and preschool children, is thought to promote marital stability because they demand intensified sex role specialisation and spousal interdependence. Childrearing has long been considered women's work in China. Despite increasing female education and labour market participation, an uneven distribution of domestic labour persists to this day (Zuo \& Bian, 2001). This has, however, rarely been perceived as an important source of conflict within the marital union by either men or women (Zheng, 1997). Zuo and Bian (2001) argue that gender-role expectations in Chinese society release husbands from sharing household responsibility equally, and wives from an equal breadwinning responsibility. In contrast, a low level of sex role specialisation, for instance, a husband's failure to fulfil the main provider role, is at odds with gender-role expectations, and is linked with increased conflict within marriage. Thus, intensified sex role specialisation with the presence of young children is likely to stabilise rather than destabilise marriage in the Chinese context. Compared to older children, infant and preschool children may have a stronger divorce inhibiting effect (Hypothesis 2). Since the effect of children's age on marriage stability has been shown to vary by 
parity (Waite \& Lillard, 1991), an interaction between parity and age of children is tested.

Preference for sons has been an enduring feature of the Chinese family. In the past, son preference resulted in high female infant and child mortality (Lee \& Wang, 1999). Since the introduction of the One Child Policy, persistent son preference has manifested in a widespread practice of sex-selective abortion in favour of boys. By the turn of this century, the national sex ratio at birth had reached 120 , one of the highest observed in the world (Attané, 2009). Son preference in China is considered a predominantly rural phenomenon (Greenhalgh \& Li, 1995). Greenhalgh and Li's survey found that the majority of rural residents said that they wanted at least one boy. A more recent survey showed persistent son preference in rural areas (Wang et al., 2013). Rural mothers with no boys often recalled strong social punishment. Some noted that not having boys was a source of conflict between themselves and their husbands' parents, which strained married couple relationships. It is expected that families with no boys would have a higher risk of divorce than families with one or more boys, especially among rural residents (Hypothesis 3 ).

Hypotheses 1 through 3 are concerned with the direct effects of marital births on the risk of divorce, net of joint determination. As noted earlier, Lillard and Waite (1993) cautioned as to the potential for reverse causation in the relationship between children and divorce. Women in a turbulent relationship more prone to divorce, may postpone or avoid childbearing within the relationship. To account for this possibility, two measures are taken in this study. Firstly, attention is paid to the temporal ordering of women's multiple marriages, births and divorces. Secondly, divorce and childbearing following marital conception are jointly modelled to control for unobserved characteristics that simultaneously affect a woman's risk of marital disruption and her chance of conceiving within that marriage.

Over recent decades, rising divorce was accompanied by rapid increase in nontraditional family behaviours, including premarital cohabitation and childbearing (Ma et al., 2018; Yu \& Xie, 2015). These changes in family behaviours were generally attributed to ideational shifts associated with economic liberalisation and globalisation. On an individual level, those engaging in cohabitation, premarital sex and childbearing were considered to possess more individualistic traits and weaker adherence to traditional family norms (Yu \& Xie, 2015), which could predispose them to more readily dissolving unhappy marriages. In other words, individuals with experience of premarital sex and pregnancy are likely to be selected into marital dissolution (Hypothesis 4a). Becker et al. (1977) posit that premarital pregnancy has a direct causal effect on the risk of divorce because women with premarital conceptions have an incentive to marry quickly and therefore are more likely to accept a mismatch. Empirical evidence in Western societies have not supported an independent effect of premarital pregnancy (as opposed to premarital births) on martial stability. In China, however, owing to strong social punishment for women with nonmarital sexual experiences (Jeffrey, 2006), and persistent policy discrimination against children born out of wedlock (Xu, 2019), premarital conception may generate intense societal and familial pressure for women to quickly marry before the child was born. This may indeed increase the risk of women hastily entering less than ideal unions. It is therefore expected that premarital conceptions will elevate 
the risk of divorce net of selection effect (hypothesis 4b). This analysis will jointly model divorce and childbearing following nonmarital conception to discern direct effects from selectivity.

Waite and Lillard (1991) have found that stepchildren tend to destabilise marriage, for they embody little marital-specific capital and could potentially increase conflict within the marital union. Children from previous relationships are therefore expected to increase the risk of divorce in China (Hypothesis 5).

\section{Data and empirical model}

\section{Data}

The present study uses data from the 2010, 2012 and 2014 waves of the CFPS. The CFPS is a nationwide, longitudinal social survey launched by the Institute of Social Science Survey of Peking University. The survey collects information on individuals' socioeconomic characteristics, family backgrounds and marital and fertility histories. All three waves of the CFPS are pooled to construct a sample of women using an individual's most up-to-date information. In the analysis of divorce, never-married women are excluded. The final sample consists of 17,974 female respondents and 18,377 marriage spells. The temporal orderings of women's multiple marriages, divorces and births were constructed using recorded dates of marriage, divorce and each birth (to the month). The CFPS also recorded the sex of each child, which facilitated study of the effects of children's sex composition on divorce. This study differentiates between childbearing following marital and nonmarital conceptions. The former includes all conceptions that occurred within marriage spells, while the latter includes children that were conceived outside of marriage, even if subsequently born within marriage spells. The date of a child's conception of is calculated as the date of birth minus 9 months.

\section{Empirical model}

One of main concerns of this study is to analyse direct effects of children on the risk of divorce and to test the existence of selection effects. To do so, a multi-process modelling technique developed by Lillard and colleagues (Lillard, 1993; Lillard \& Waite, 1993; Upchurch et al., 2002) is adopted. This method is well suited to the purpose of this research, since direct effects can be disentangled from selection effects as long as the functional form of the unobserved error term is assumed to follow a multivariate normal distribution. The present analysis jointly models marital dissolution with fertility processes that produce key determinants of interest: the number and age/sex composition of children, and premarital conception. Marital and nonmarital childbearing are included as separate processes to test for the existence of unobserved individual characteristics that simultaneously affect divorce and childbearing behaviours within marital unions, and divorce and non-traditional family behaviours. Since the timing and duration of marriage are important determinants 
of divorce (Ma et al., 2018; Waite \& Lillard, 1991), the process of divorce is jointly modelled with marriage formation. The data analysis is done using aML software created by Lillard and Panis (2000).

The resulting model consists of four simultaneous continuous-time hazard equations for an individual's waiting time to, nonmarital childbearing, marriage, martial childbearing and divorce. For the divorce processes, the waiting time to divorce (months) starts from the beginning of a marriage until the end of the marriage through divorce or when the observation is censored (including when a marriage ends in widowhood). For marriage, the waiting time includes duration from age 12 until a marriage occurs or the observation is censored, and duration from the termination of a marriage through divorce or death of the husband until another marriage occurred or the observation is censored. A woman is at risk of marital childbearing from age 12 onwards whenever she is married and not pregnant. Similarly, a woman is at risk of nonmarital childbearing from age 12 onwards whenever she is not married and not pregnant.

All four equations are multilevel in nature because individuals could have multiple marriages and divorces as well as more than one conception that occurred within or out of wedlock. In the analysis of recurring events there is a need to account for individual-level heterogeneity. Therefore, each equation includes a women-level residual. The issue of selectivity arises when unobserved women-level characteristics simultaneously affect more than one family process. This is addressed by allowing the residual terms to correlate across processes.

Although all four equations stand on an equal footing, the following focuses on the equation specifying the log-hazard of divorce, which is the main focus of this study. Full model specifications and estimations are available from the author upon request. The log-hazard of divorce is specified as follows:

$$
\begin{aligned}
\operatorname{Inh}_{k}(t)= & \alpha_{0}+\gamma_{1}^{\prime} \text { DurMar }(t)+\gamma_{2}^{\prime} \text { Time }(t)+\gamma_{3}^{\prime} \text { Age }(t)+\gamma_{4}^{\prime} \text { AgeChild }(t) \\
& +\alpha_{1} \text { Parity }+\alpha_{2} \text { ParityPreviousMar }+\alpha_{3} \text { SexCompostion } \\
& +\alpha_{4} \text { PreMarConception }+\alpha_{6} X_{k}+\epsilon,
\end{aligned}
$$

The hazard equation is defined for the point in time at which the woman is at risk of divorce. Subscripts $k$ denote multiple spells of marriage until a divorce occurs or the observation is censored. The first line of the specification includes the intercept and four duration dependencies: the duration of each marriage spell (DurMar(t)), calendar time $(\operatorname{Time}(\mathrm{t}))$, woman's age $(\operatorname{Age}(\mathrm{t}))$ and the time since a child was born (AgeChild(t)). Duration dependencies enter the equation cumulatively. At first only woman's age, calendar time and duration since marriage enter the equation. But once a child is born the duration since the birth (i.e., the child's age) also enters it. Similarly, second and higher order parities enter cumulatively if and when they occur. To test whether the effects of children's age on divorce vary by parity, AgeChild(t) is estimated separately for the first, second, and third and higher order births. This analysis is primarily interested in children who belong to both parents. Therefore, AgeChild(t) does not include the effects of stepchildren from previous marriages. Duration dependencies enter the equation as piecewise linear splines, with vector $\gamma$ ' denoting the nodes of the splines. 
As shown in the second and third lines of the above equation, main covariates of interest include the number of children in the current marriage spell (Parity), sex composition of children (SexComposition), premarital conception (PreMarConception) and number of children from previous marriages (ParityPreviousMar).

'Parity' denotes the number of children from the current marriage. It is a categorical variable containing three categories: no children, one child, and two or more children. The variable is constructed as a categorical variable to test whether childlessness significantly elevates the risk of divorce, and whether the second and higher order births have different effects on divorce than the first birth. Since the number of births could change throughout a marriage spell, this variable is time varying. It does not include stepchildren. The number of stepchildren is denoted by 'ParityPreviousMar'.

'SexComposition' consists of two variables. The first indicates sex composition of children in families with only one child. It contains three categories: 1 boy, 1 girl, and sex of child missing. The second variable denotes sex composition of children in families with two or more children. It has four categories: all boys, all girls, both boys and girls, and unknown-missing data. Which one of the two variables enters the equation depends on the total number of children born in a family: in one-child families, the first variable enters the equation, but the second takes the value zero; in larger families the opposite occurs. This variable is estimated separately for rural and urban women.

Premarital conception (PreMarConception) is included as a categorical variable consisting of three categories: none of the children belonging to both parents were conceived outside of marriage, a child born in the current marriage was conceived before marriage, one or more children were born prior to entering marriage. This variable does not enter the equation for childless women.

$X_{k}$ represents control covariates. Important control variables included in this analysis are age at first marriage, age gap between the husband and wife, whether a marriage was arranged, woman's education attainment, woman's household registration or hukou status and region of residence at age 12, woman's ethnicity, whether a marriage was preceded by a period of cohabitation, and whether a marriage was the first marriage. Previous studies have emphasised that education attainment is an important factor influencing not only the risk of divorce (Ma et al., 2018), but also fertility behaviours (Greenhalgh \& Li, 1995). This study tests interactions between women's education attainment and the number of children as well as children's sex composition. They were not statistically significant, and therefore not included in the final models. Appendix Table 3 provides a summary of descriptive statistics of the covariates.

The error term $\epsilon$ captures women-specific heterogeneity. This analysis compares two sets of estimations. The first (Model 1) does not include correlated womenspecific heterogeneity. This model is a standard specification in event-history studies. The full model (Model 2) accounts for joint determination by allowing womenspecific heterogeneity to correlate across processes. A comparison across models reveals potential bias without controlling for selection effects. 


\section{Results}

Table 1 shows the results of the log-hazard of divorce. Unless otherwise noted, results refer to estimations in the full model (Model 2).

\section{Effects of the presence and number of children}

The second section of Table 2 shows the findings for the number of children separately for rural and urban women. Consistent with Hypothesis 1a, having the first child significantly reduces the risk of parental divorce compared to being childless for both rural and urban women, after controlling for other confounding variables including duration of marriage and selection effects (Model 2). Although not shown in Table 1, having two or more children also reduces the risk of divorce when compared a childless reference group (rural, coef. $-2.78, p<0.05$, urban, coef. -2.08 , $p>0.10)$.

The effect of the presence of children on divorce is slightly weaker after accounting for selectivity. The error structure reported in Table 2 shows the processes of divorce and childbearing following marital conception to be negatively correlated. Perhaps the quality of a marital relationship, which was unobserved in the data, affects women's likelihood of conceiving within that marriage. Or perhaps a woman's unobserved characteristics, such as her adherence to traditional family values, positively affects her likelihood of having a marital conception but negatively influences her chance of dissolving an unhappy marriage. Whatever the mechanism, divorce and martial childbearing are intertwined family processes, and without accounting for joint determination, coefficient estimation using the standard eventhistory approach slightly overestimates the marriage stabilising effect of having children.

Consistent with hypothesis $1 \mathrm{~b}$, whereas the first child is shown to significantly lower the risk of marital disruption among urban women, the marriage-protective effect of having additional children is not statistically significant. Even for rural women who were generally allowed to have more than one child, having a second or higher order birth does not significantly improve marriage stability. Similar to the finding of Waite and Lillard (1991), the firstborn child is shown to exert the most significant marriage stabilising effect.

\section{The effect of children's age}

Contrary to hypothesis 2, this analysis finds no significant effect of children's age on parental divorce. Unlike Western societies, children's protective effects on marriage in China does not seem to fade nor disappear as they age. Regardless of parity, older children have similar effects to infant and preschool children on marital stability. This finding does not lend support for the arguments that younger children stabilise marriage more so than older children, as they embody more marital-specific capital or encourage sex role specialisation. Rather, having a child in China reduces divorce risk irrespective of its age. 
Table 1 Divorce hazard estimates

\begin{tabular}{|c|c|c|c|c|}
\hline \multirow[t]{2}{*}{ Covariates } & \multicolumn{2}{|l|}{ Model 1} & \multicolumn{2}{|l|}{ Model 2} \\
\hline & Coef & SE & Coef & SE \\
\hline \multicolumn{5}{|l|}{ Children } \\
\hline \multicolumn{5}{|c|}{ Number of children (ref: 1 child) } \\
\hline \multicolumn{5}{|l|}{ Rural } \\
\hline Childless & $1.46^{* * *}$ & 0.51 & $1.43^{* * *}$ & 0.51 \\
\hline 2 children & -1.31 & 1.04 & -1.32 & 1.04 \\
\hline $3+$ children & -1.10 & 1.31 & -1.11 & 1.31 \\
\hline \multicolumn{5}{|l|}{ Urban } \\
\hline Childless & $1.27 * * *$ & 0.57 & $1.24 * * *$ & 0.57 \\
\hline 2 children & -0.73 & 1.28 & -0.75 & 1.28 \\
\hline $3+$ children & -1.16 & 1.91 & -1.12 & 1.91 \\
\hline \multicolumn{5}{|c|}{ Children's age (Duration since a child was born) } \\
\hline \multicolumn{5}{|l|}{ Parity 1} \\
\hline $0-1$ year (slope) & 0.39 & 0.58 & 0.48 & 0.58 \\
\hline $1-5$ years (slope) & 0.02 & 0.08 & 0.04 & 0.08 \\
\hline 5-10 years (slope) & -0.04 & 0.04 & -0.03 & 0.04 \\
\hline$\geq 10$ years (slope) & 0.00 & 0.02 & 0.00 & 0.02 \\
\hline \multicolumn{5}{|l|}{ Parity 2} \\
\hline $0-1$ year (slope) & 0.62 & 1.18 & 0.69 & 1.18 \\
\hline $1-5$ years (slope) & 0.18 & 0.19 & 0.18 & 0.19 \\
\hline $5-10$ years (slope) & -0.04 & 0.09 & -0.04 & 0.09 \\
\hline$\geq 10$ years (slope) & -0.02 & 0.02 & -0.02 & 0.02 \\
\hline \multicolumn{5}{|l|}{ Parity $3+$} \\
\hline 0-1 year (slope) & -1.62 & 1.47 & -1.60 & 1.48 \\
\hline $1-5$ years (slope) & 0.43 & 0.39 & 0.43 & 0.39 \\
\hline $5-10$ years (slope) & -0.08 & 0.16 & -0.08 & 0.16 \\
\hline$\geq 10$ years (slope) & 0.02 & 0.02 & 0.02 & 0.02 \\
\hline
\end{tabular}

Children's sex composition

Family with 1 child (ref: 1 girl)

Rural

\begin{tabular}{lllll}
1 boy & $-0.76^{* *}$ & 0.18 & $-0.77^{* *}$ & 0.18 \\
Missing & -0.23 & 0.22 & -0.23 & 0.22 \\
Urban & & & & \\
1 boy & -0.15 & 0.23 & -0.14 & 0.23 \\
Missing & 0.01 & 0.24 & 0.01 & 0.25 \\
Family with more than 2 children (ref: only girls) & & & \\
Rural & & & & \\
Only boys & $-1.83^{* * *}$ & 0.41 & $-1.81^{* * *}$ & 0.41 \\
Boys and girls & $-1.68^{* * *}$ & 0.30 & $-1.65^{* * *}$ & 0.31 \\
Unknown & $-2.37^{* * *}$ & 0.59 & $-2.34^{* * *}$ & 0.60 \\
Urban & & & & \\
Only boys & -0.38 & 0.89 & -0.34 & 0.90 \\
\hline
\end{tabular}


Table 1 (continued)

\begin{tabular}{|c|c|c|c|c|}
\hline \multirow[t]{2}{*}{ Covariates } & \multicolumn{2}{|l|}{ Model 1} & \multicolumn{2}{|l|}{ Model 2} \\
\hline & Coef & SE & Coef & SE \\
\hline Boys and girls & -1.33 & 0.94 & -1.29 & 0.94 \\
\hline Unknown & -0.61 & 0.90 & -0.57 & 0.90 \\
\hline \multicolumn{5}{|c|}{ Premarital conception (ref: no premarital conception) } \\
\hline Marital birth conceived before marriage & 0.12 & 0.15 & -0.23 & 0.23 \\
\hline nonmarital births & $0.66^{* * * *}$ & 0.22 & 0.21 & 0.31 \\
\hline Children born in previous marriages & 0.16 & 0.67 & 0.28 & 0.70 \\
\hline \multicolumn{5}{|l|}{ Other determinants } \\
\hline \multicolumn{5}{|l|}{ Duration of marriage } \\
\hline $0-1$ year (slope) & $1.35^{*}$ & 0.70 & $1.33^{*}$ & 0.71 \\
\hline $1-3$ years (slope) & $0.36 * *$ & 0.16 & $0.35^{* *}$ & 0.16 \\
\hline $3-6$ years (slope) & -0.07 & 0.09 & -0.07 & 0.09 \\
\hline$\geq 6$ years (slope) & -0.04 & 0.03 & -0.04 & 0.03 \\
\hline \multicolumn{5}{|l|}{ Calendar time } \\
\hline Prior to 1966 (slope) & 0.19 & 0.13 & 0.19 & 0.13 \\
\hline 1966-1976 (slope) & -0.13 & 0.09 & -0.13 & 0.09 \\
\hline 1976-2000 (slope) & $0.16^{* * *}$ & 0.05 & $0.16^{* * *}$ & 0.05 \\
\hline After 2000 (slope) & $0.05^{* * *}$ & 0.01 & $0.05^{* * * *}$ & 0.01 \\
\hline \multicolumn{5}{|l|}{ Wife's age } \\
\hline 14- 20 years (slope) & 0.07 & 0.15 & 0.06 & 0.15 \\
\hline 20-25 years (slope) & -0.03 & 0.08 & -0.06 & 0.08 \\
\hline 25-30 years (slope) & $0.13^{* * *}$ & 0.05 & $0.11^{*}$ & 0.06 \\
\hline$\geq 30$ years (slope) & -0.02 & 0.02 & -0.03 & 0.03 \\
\hline \multicolumn{5}{|l|}{ Wife's age at first marriage (ref: 20-25 years) } \\
\hline 14-20 years & 0.20 & 0.21 & 0.24 & 0.21 \\
\hline $25-30$ years & -0.26 & 0.16 & $-0.32 *$ & 0.16 \\
\hline $30+$ years & -0.28 & 0.38 & -0.32 & 0.38 \\
\hline \multicolumn{5}{|c|}{ Age dif. between husband and wife (ref: wife and husband born in the same year) } \\
\hline Husband older & -0.05 & 0.13 & -0.04 & 0.13 \\
\hline Wife older & 0.03 & 0.15 & 0.01 & 0.15 \\
\hline Missing & $2.49^{* * *}$ & 0.14 & $2.48 * * *$ & 0.14 \\
\hline \multicolumn{5}{|c|}{ How couples meet (ref: arranged or introduced) } \\
\hline By themselves & 0.05 & 0.10 & 0.06 & 0.10 \\
\hline Missing & $-0.50 *$ & 0.26 & $-0.49^{*}$ & 0.26 \\
\hline \multicolumn{5}{|l|}{ Education (ref: illiterate) } \\
\hline Primary school & $0.28 *$ & 0.16 & $0.30 *$ & 0.16 \\
\hline Middle school & $0.37 * *$ & 0.15 & $0.42^{* * *}$ & 0.15 \\
\hline High school & $0.40 * *$ & 0.17 & $0.49^{* * * *}$ & 0.18 \\
\hline Bachelor's degree and higher & 0.26 & 0.29 & 0.39 & 0.30 \\
\hline \multicolumn{5}{|l|}{ Hukou (ref: rural) } \\
\hline Urban & 0.18 & 0.22 & 0.22 & 0.22 \\
\hline
\end{tabular}


Table 1 (continued)

\begin{tabular}{|c|c|c|c|c|}
\hline \multirow[t]{2}{*}{ Covariates } & \multicolumn{2}{|l|}{ Model 1} & \multicolumn{2}{|l|}{ Model 2} \\
\hline & Coef & SE & Coef & SE \\
\hline \multicolumn{5}{|l|}{ Ethnicity (ref: Han ethnicity) } \\
\hline Other ethnic groups & 0.20 & 0.18 & 0.21 & 0.18 \\
\hline Missing & -1.27 & 0.81 & -1.23 & 0.81 \\
\hline \multicolumn{5}{|c|}{ Region of residence (ref: middle inland) } \\
\hline Beijing, Tianjin, Shanghai & 0.15 & 0.19 & 0.22 & 0.19 \\
\hline Eastern coastal region & $-0.32 *$ & 0.19 & -0.28 & 0.19 \\
\hline Northern region & $0.26^{*}$ & 0.15 & $0.26^{*}$ & 0.15 \\
\hline Western region & 0.09 & 0.16 & 0.08 & 0.16 \\
\hline Missing & 0.12 & 0.25 & 0.16 & 0.26 \\
\hline Premarital cohabitation & 0.10 & 0.16 & 0.00 & 0.17 \\
\hline Remarriage & -0.30 & 0.41 & -0.10 & 0.42 \\
\hline Constant & $-11.02 * * *$ & 1.28 & $-10.85 * * *$ & 1.31 \\
\hline Log likelihood & $-261,221.20$ & & $-257,711.62$ & \\
\hline No. of subjects & 17,974 & & 17,974 & \\
\hline No. of marriages & 18,377 & & 18,377 & \\
\hline No. of divorces & 511 & & 511 & \\
\hline
\end{tabular}

${ }^{*} p<.1 ; * * p<.05 ; * * * p<.01$

Table 2 Error structure in Model 2

\begin{tabular}{lcc}
\hline Unobserved heterogeneity $(\epsilon)$ & SE \\
\hline Divorce & $0.28^{*}$ & 0.16 \\
Correlations & & \\
Divorce-Marital conception & $-0.86^{* * *}$ & 0.03 \\
Divorce-Nonmarital conception & $0.38^{* * *}$ & 0.04 \\
Divorce-Marriage & $-0.73 * * *$ & 0.02 \\
\hline
\end{tabular}

$* p<.1 ; * * p<.05 ; * * * p<.01$

\section{The effect of children's sex composition}

Children's sex composition was found to have a strong influence on martial stability, but only in rural China. For rural women with one child, having a boy sharply reduces the risk of divorce comparing to those with only one girl. For rural women with two or more children, those with only boys have the lowest risk of divorce, followed by families with both boys and girls, whereas families with only girls have the highest risk of divorce. The strong marriage stabilising effect of having boys reflects persistent son-preference in rural China. It is a finding that echoes evidence for India (another patriarchal society with strong son preference), for which Bose and Smith (2003) showed an increased risk of divorce among families with only girls compared to those with at least one boy. In contrast, children's sex composition has no 
significant effect on marital stability among urban women. As previously noted, son-preference has been stronger in rural China. Not having a boy potentially causes greater strain to marriages of rural couples than to those of their urban counterparts.

\section{The effect of premarital conception}

Using a standard event-history approach (Model 1), the results show that a premarital birth significantly increases the risk of disruption, but a premarital conception leading to a marital birth has no significant disruptive effect. Previous findings of a disruptive effect of premarital conception in China (Ma et al., 2018; Xu et al., 2015) reflect the contribution of these premarital pregnancies that transitioned into out of wedlock births. A comparison between Model 1 and Model 2, however, reveals the extent to which estimates of the effect of premarital conception were biased without accounting for joint determination. After controlling for selectivity, whether a child was conceived before marriage (regardless of whether it was born within or before marriage) has no significant causal effect on the risk of divorce. The error structure in Table 2 further shows that the processes of divorce and childbearing following nonmarital conception are positively correlated, indicating the existence of unobserved individual characteristics that influence the risk of nonmarital conception and divorce in similar ways. Consistent with Hypothesis $4 \mathrm{a}$, women with non-traditional sexual and childbearing behaviours are selected into divorce.

Contrary to Hypothesis $4 \mathrm{~b}$, there is no evidence of a significant direct effect of premarital pregnancy on divorce net of selection effects. This is perhaps owing to the nature of premarital conceptions in China. Although not shown in Table 2, the processes of childbearing following nonmarital conception and marriage formation were significantly and positively correlated, with a correlation coefficient of 0.24 $(p<0.01)$. Previous studies in the US have argued that the existence of positive unobserved correlation between marriage and nonmarital conception could potentially indicate a broader family building strategy (Brien et al., 1999; Musick, 2007). In other words, women who became pregnant before marriage may have had plans to marry. In the scenario where an event of premarital pregnancy may be planned, it is less likely to have a significant disruptive effect on marital stability.

\section{The effects of children from previous relationships}

Hypothesis 5 posits that the presence of stepchildren increases the risk of divorce. The results suggest that children from previous marriages elevated the risk of divorce after controlling for selection effects, but this effect is not statistically significant. 


\section{Other determinants of divorce}

Consistent with Waite and Lillard (1991) and Lillard and Waite (1993), this study finds that the risk of divorce in China is highest during the first three years of marriage. Duration dependency for women's age suggests that women's risk of divorce increases most sharply between ages 25 and 30 years. The duration dependency for calendar time further demonstrates temporal shifts in the risk of divorce in China. This risk sharply declined during the Cultural Revolution (1966-1976), when the state intensified its intervention in personal affairs. During this period divorce was only allowed under limited circumstances (Diamant, 2000). Divorce has risen since the late 1970s, and again since the turn of this century. In line with the findings in $\mathrm{Mu}$, Turunen \& Rizzi (2018), this analysis finds that women married as teenagers had a higher risk of divorce than those married between ages 20 and 25, whereas those married after age 25 had a lower risk of divorce again. Compared to illiterate women, those with primary, middle or higher school educational attainment have a higher risk of divorce.

Premarital cohabitation experience has no significant association with divorce risk after accounting for the effects of premarital conceptions. Compared to the first marriage, remarriage does not have a significant impact on marital stability. Significant associations between divorce and the missing categories of two variables (age gap between husband and wife and how the couple met) hinders meaningful interpretation. Perhaps women who had experienced divorce were less likely or less willing to recollect information pertaining to their former spouses.

\section{Summary}

Past work in the US has suggested that marriage, divorce and childbearing are interrelated family processes (Lillard \& Waite, 1993; Upchurch et al., 2002). Children could affect a couple's likelihood of ending their marriage, but at the same time, women in turbulent relationships may deliberately postpone or avoid childbearing. Unobserved factors such as personal traits and value orientations could also simultaneously influence one's risk of divorce as well as marriage and childbearing behaviours. A person with more individualistic traits and less traditional family values could be more prone to both premarital conception and divorce compared to those attaching greater importance to traditional family and sexual norms. Ignoring the potential of selection effects could bias estimates of children's effects on marital dissolution. This analysis estimated a joint model of marital dissolution with marriage formation, childbearing following marital and nonmarital conception to discern direct effects of children from selectivity. Several direct effects of children on the risk of subsequent divorce were examined including the presence and number of children, their ages and sex composition, and childbearing following nonmartial conception. The results confirmed the existence of unobserved factors that affect marital dissolution and childbearing outcomes and demonstrated the extent to which estimates of direct effects were confounded by joint determination. 
As anticipated, childlessness was found to significantly elevate the risk of divorce net of selection effect. Children could deter disruption by increasing the financial and/or psychic costs associated with divorce. At the same time, under the influence of Confucian family norms, it is likely that having children is considered a central component of what constitutes a wholesome and happy marriage. Not having any children could itself become a source of strain in a marital relationship. In traditional China, divorce was socially prohibited and yet allowed when the wife could not bear children. Until this day, the importance of children remains little diminished. The positive association between childlessness and divorce may be attributable to the paramount importance attached to having children.

The results further suggested that whereas the first child markedly reduces the risk of divorce, having additional children does not significantly improve marital stability. For urban women, this reflects low occurrence of second and higher order births since the introduction of the One Child Policy. Even for rural women who were generally allowed to have more than one child, having two or more children does not significantly affect the survival of marriage compared to women with only one child. In China, having at least one child stabilises marriage, but children's marriage stabilising effect does not increase linearly with the number of children.

There was no evidence that children's marriage-stabilising effect declines as they age. Considered by itself, children's age does not have an independent effect on the survival of marriage, regardless of parity. This perhaps further highlights the cultural importance of having children in China, so that children, as a form of maritalspecific capital, do not diminish in value as they grow older. Only their absence has a significant disruptive effect on marriage.

Given persistent son preference in rural China, it is not surprising that the risk of marital disruption was found to be markedly higher among families with only girls compared with those with at least one boy. For urban women, however, children's sex composition had little effect on marital stability.

Perhaps the most innovative finding of this study pertains to the association between premarital conception/birth and marital disruption, and the extent to which this association can be attributed to a selection effect. Before controlling for selectivity, premarital births were found to significantly increase the risk of divorce, although premarital pregnancies leading to marital births did not affect divorce risk. However, whether a child was conceived or born prior to entry into marriage had no significant causal effect on marital stability after joint determination was accounted for. Meanwhile, a strong and positive residual correlation between the processes of divorce and nonmarital conception indicated the existence of individual-level heterogeneity that simultaneously affected both processes. In China, there is a potential selection of women with non-traditional family behaviours into marital dissolution.

It is important to acknowledge the limitations of this study. Firstly, the analysis only included data for women. Husbands' socioeconomic characteristics and family backgrounds were not included as control variables, although they could influence the risk of marital disruption. Secondly, a large proportion of marriage spells were censored, and a relatively small percentage of marriages ended in divorce. Low occurrences of divorce in the final sample may affect the generalisability of this 
research. Given rising divorce in contemporary China, it will be valuable to replicate this analysis when future waves of the CFPS become available.

\section{Appendix}

See Table 3.

Table 3 Descriptive statistics of the main predictors of divorce risk $^{\mathrm{a}}$
Covariates: Children

Number of children (\%)

Rural

Childless

6.75

1 child

31.61

2 children

38.04

3 or more children

23.60

Urban

Childless

12.71

1 child

67.70

2 children

13.13

3 or more children

6.46

Children's age (mean)

21.85

Censored spell

Divorce spell

10.94

Children's Sex composition (\%)

1 child family -rural

1 girl

1 boy

Missing

18.79

1 child family -urban

1 girl

30.86

1 boy

38.74

Missing

30.39

Families with 2 and more children-rural

All girls

10.12

All boys

16.51

Both boys and girls

58.84

Missing

14.53

Families 2 and more children-urban

All girls

All boys

15.05

Both boys and girls

46.59

Missing 
Table 3 (continued)
Covariates: Children

Number of children (\%)

Premarital conception (\%)

No premarital conception

74.88

Marital birth conceived before marriage

17.78

Nonmarital birth

7.34

Number of children born in previous marriage (mean)

1.16

Other Covariates

Duration of marriage (mean)

Divorce spell

Censored spell

Calendar time (\%)

Prior to 1966

9.89

1966 to 1976

13.18

1977 to 1999

47.12

2000 to 2014

29.82

Wife's age (mean)

46.52

Wife's age at marriage (\%)

14-19 years

20-24 years

57.76

25-30 years

14.32

Older than 30 years

4.03

Age difference between husband and wife (\%)

Husband older

Husband and wife born in the same year

16.38

Wife older

16.37

Missing

How couples meet (\%)

Arranged or introduced by relatives $\quad 61.91$

By themselves

35.25

Missing

2.84

Wife's education (\%)

Illiterate

36.94

Primary school

19.57

Middle school

High school

15.90

Bachelor's degree and higher

2.64

Hukou at age 12 (\%)

Rural

Urban

Ethnicity (\%)

Han

Other ethnic groups

Missing 
Table 3 (continued)

\begin{tabular}{ll}
\hline Covariates: Children & \\
\hline Number of children (\%) & \\
\hline Region of residence (\%) & 7.59 \\
Beijing, Tianjin, Shanghai & 17.95 \\
Eastern coastal region & 23.66 \\
Middle inland & 20.67 \\
Northern region & 26.98 \\
Western region & 3.16 \\
Missing & 10.88 \\
Premarital cohabitation (\%) & 2.20 \\
Remarriage (\%) & 18,389 \\
Total marriage spell & 17,974 \\
Total number of women
\end{tabular}

${ }^{a}$ All covariates measured at the time of divorce or censoring, except for calendar time which is measured at the start of a marriage spell

Funding Open Access funding enabled and organized by CAUL and its Member Institutions.

Open Access This article is licensed under a Creative Commons Attribution 4.0 International License, which permits use, sharing, adaptation, distribution and reproduction in any medium or format, as long as you give appropriate credit to the original author(s) and the source, provide a link to the Creative Commons licence, and indicate if changes were made. The images or other third party material in this article are included in the article's Creative Commons licence, unless indicated otherwise in a credit line to the material. If material is not included in the article's Creative Commons licence and your intended use is not permitted by statutory regulation or exceeds the permitted use, you will need to obtain permission directly from the copyright holder. To view a copy of this licence, visit http://creativecommons.org/licen ses/by/4.0/.

\section{References}

Andersson, G. (1997). The impact of children on divorce risks of Swedish women. European Journal of Population, 13, 109-145.

Andersson, G., \& Woldemicael, C. (2001). Sex com- position of children as a determinant of marriage disruption and marriage formation: Evidence from Swedish register data. Journal of Population Research, 18, 143-153.

Attané, I. (2009). The determinants of discrimination against daughters in China: Evidence from a provincial-level analysis. Population Studies, 63(1), 87-102.

Axinn, W. G., \& Thornton, A. (1992). The relationship between cohabitation and divorce: Selectivity or causal influence? Demography, 29(3), 357-374.

Baizán, P., Aassve, A., \& Billari, F. C. (2003). Cohabitation, marriage, and first birth: The interrelationship of family formation events in Spain. European Journal of Population/revue Européenne De Démographie, 19(2), 147-169. https://doi.org/10.1023/A:1023343001627

Becker, G. S., Landes, E. M., \& Michael, R. T. (1977). An economic analysis of marital instability. The Journal of Political Economy, 85(6), 1141-1187.

Berrington, A., \& Diamond, I. (1999). Marital dissolution among the 1958 British Birth cohort: The role of cohabitation. Population Studies, 53(1), 19-38.

Bose, S., \& South, S. J. (2003). Sex composition of children and marital disruption in India. Journal of Marriage and Family, 65(4), 996-1006. https://doi.org/10.1111/j.1741-3737.2003.00996.x

Bracher, M., Santow, G., Morgan, S. P., \& Trussell, J. (1993). Marriage dissolution in Australia: Models and explanations. Population Studies, 47, 403-425. 
Brien, M. J., Lillard, L. A., \& Waite, L. J. (1999). Interrelated family-building behaviors: Cohabitation, marriage, and nonmarital conception. Demography, 36(4), 535-551. https://doi.org/10.2307/26480 89

Cherlin, A. (1977). The effect of children on marital dissolution. Demography, 14(3), 265-272.

Cohan, C. L., \& Kleinbaum, S. (2002). Toward a greater understanding of the cohabitation effect: Premarital cohabitation and marital communication. Journal of Marriage and Family, 64(1), 180-192.

Diamant, N. J. (2000). Revolutionizing the family: Politics, love, and divorce in urban and rural China, 1949-1968. University of California Press.

Diekmann, A., \& Engelhardt, H. (1999). The social inheritance of divorce: Effects of parent's family type in post-war Germany. American Sociological Review, 64, 783-793.

Greenhalgh, S., \& Li, J. (1995). Engendering reproductive China: For a feminist demography of reproduction. Signs: Journal of Women in Culture and Society, 20(3), 601-641.

Gu, B., Wang, F., Guo, Z., \& Zhang, E. (2007). China's local and national fertility policies at the end of the twentieth century. Population and Development Review, 129-147.

Heaton, T. B. (1990). Marital stability throughout the child-rearing years. Demography, 27(1), 55-63.

Huang, P. C. (2005). Divorce law practices and the origins, myths, and realities of judicial "mediation" in China. Modern China, 31, 151-203. https://doi.org/10.1177/0097700405274585

Jeffreys, E. (2006). Talking sex and sexuality in China. In E. Jeffreys (Ed.), Sex and sexuality in China (pp. 1-20). Routledge.

Kahn, J. R., \& London, K. A. (1991). Premarital sex and the risk of divorce. Journal of Marriage and the Family, 845-855.

Lee, J. Z., \& Wang, F. (1999). One quarter of humanity: malthusian mythology and Chinese realities, 1700-2000. Cambridge: Harvard University Press.

Leone, T., \& Hinde, A. (2008). Fertility and union dissolution in Brazil: an example of multi-process modelling using the demographic and health survey calendar data. Demographic Research, 17, $157-180$.

Levinger, G. (1965). Marital cohesiveness and dissolution: An integrative review. Journal of Marriage and the Family, 27, 19-28.

Lillard, L. A. (1993). Simultaneous equations for hazards: Marriage duration and fertility timing. Journal of Econometrics., 56, 189-217.

Lillard, L. A., Brien, M. J., \& Waite, L. J. (1995). Premarital cohabitation and subsequent marital dissolution: A matter of self-selection? Demography, 32, 437-457.

Lillard, L. A., \& Panis, C. W. (2000). aML Multiprocess Multilevel Statistical Software, Release 1. Los Angeles: EconWare.

Lillard, L. A., \& Waite, L. J. (1993). A joint model of marital childbearing and marital disruption. Demography, 30(4), 653-681.

Ma, L., Turunen, J., \& Rizzi, E. (2018). Divorce Chinese Style. Journal of Marriage and Family, 80(5), 1287-1297.

Morgan, S. P., \& Pollard, M. S. (2002). Do parents of girls really have a higher risk of divorce? Paper presented at the annual meeting of the Population Association of America, Atlanta.

Morgan, S. P., Lye, D. N., \& Condran, G. A. (1988). Sons, daughters and the risk of marital disruption. The American Journal of Sociology, 94(1), 110-129.

Morgan, S. P., \& Rindfuss, R. R. (1985). Marital disruption: Structural and temporal dimensions. The American Journal of Sociology, 90(5), 1055-1077.

Murphy, M. J. (1985). Demographic and socio-economic influences on recent British marital breakdown patterns. Population Studies, 39(3), 441-460.

Musick, K. (2007). Cohabitation, nonmarital childbearing, and the marriage process. Demographic Research, 16, 249-286.

Parsons, T. (1949). The social structure of the family. In R. Anshen (Ed.), The family: Its function and destiny. New York: Harper and Brothers.

Platte, E. (1988). Divorce trends and patterns in China: Past and present. Pacific Affairs, 61, 428-445.

Sun, A., \& Zhao, Y. (2016). Divorce, abortion, and the child sex ratio: The impact of divorce reform in China. Journal of Development Economics, 120, 53-69. https://doi.org/10.1016/j.jdeveco.2015.11. 006

Thomson, E., \& Colella, U. (1992). Cohabitation and marital stability: Quality or commitment? Journal of Marriage and the Family, 54(2), 259-267.

Thornton, A. (1977). Children and marital stability. Journal of Marriage and the Family, 3, 531-540. 
Todesco, L. (2011). A matter of number, age or marriage? Children and marital dissolution in Italy. Population Research and Policy Review, 30(2), 313-332.

Upchurch, D. M., Lillard, L. A., \& Panis, C. W. A. (2002). Nonmarital childbearing: Influences of education, marriage, and fertility. Demography, 39, 311-329.

Waite, L. J., \& Lillard, L. A. (1991). Children and marital disruption. The American Journal of Sociology, 96(4), 930-953.

Wang, Q., \& Zhou, Q. (2010). China's divorce and remarriage rates: Trends and regional disparities. Journal of Divorce and Remarriage, 51(4), 257-267.

Wang, X., Lu, L., Dong, Z. X., Chi, Z., Wei, L., Jun, Z. W., \& Hesketh, T. (2013). Rising women's status, modernisation and persisting son preference in China. Indian Journal of Gender Studies, 20(1), 85-109. https://doi.org/10.1177/0971521512465938

Wong, L. (1982). Family reform through divorce law in the PRC. Pacific Basin Law Journal. 1(2)

$\mathrm{Xu}$, K. (2019). Changing patterns and determinants of first marriage over the history of the People's Republic of China. Population, 74(3), 205-235.

Xu, Q., Yu, J., \& Qiu, Z. (2015). The impact of children on divorce risk. The Journal of Chinese Sociology, 2(1), 1.

Yan, Y. (2003). Private Life under Socialism: Love, Intimacy, and Family Change in a Chinese Village, 1949-1999. California: Stanford University Press.

Yu, J., \& Xie, Y. (2015). Cohabitation in China: Trends and determinants. Population and Development Review, 41(4), 607-628. https://doi.org/10.1111/j.1728-4457.2015.00087x

Zeng, Y., Schultz, T. P., Wang, D. D., \& Gu, D. (2002). Association of divorce with socio-demographic covariates in China, 1955-1985: Event history analysis based on data collected in Shanghai, Hebei, and Shaanxi. Demographic Research, 7(11), 407-432. https://doi.org/10.4054/DemRes.2002.7.11

Zhang, Y. (2017). Premarital cohabitation and marital dissolution in postreform China: Cohabitation and divorce in China. Journal of Marriage and Family, 79(5), 1435-1449. https://doi.org/10.1111/jomf. 12419

Zhao, Z., Xu, Q., \& Yuan, X. (2017). Far below replacement fertility in urban China. Journal of Biosocial Science, 49(S1), S4-S19.

Zheng, X. (1997). On the phenomenon of female retreat to the home. In Y. Zhao \& L. Guo (Eds.), Social transition and women's development (pp. 113-120). Beijing: Chinese Women's Press.

Zuo, J., \& Bian, Y. (2001). Gendered resources, division of housework, and perceived fairness. A case in urban China. Journal of Marriage and Family, 63(4), 1122-1133. https://doi.org/10.1111/j.17413737.2001 .01122

Publisher's Note Springer Nature remains neutral with regard to jurisdictional claims in published maps and institutional affiliations. 